\title{
A ÉTICA DA PALAVRA ENTRE OS WAPISHANA*
}

\author{
Nádia Farage
}

No começo, dizem os Wapishana, $\underline{1}$ "quando o céu era perto, tudo falava, era puri", magia. Céu e terra eram então indiferenciados, bem como indiferenciados eram os seres que os habitavam, porque sua fala era uma só.

Era sobretudo plástico aquele mundo original, e a força de o moldar encontrava-se na palavra: "Antes falava e mudava as coisas. Tudo agora já está feito". Eficaz, criativa, a palavra provocava transformações contínuas, que deram ao mundo a feição que ele ainda hoje guarda: cachoeiras, rios, montanhas assim se criaram, em batalhas verbais entre os demiurgos.

O tempo de antes está, porém, irremediavelmente perdido. O mundo, tal como o conhecemos hoje, apresenta-se como o reverso da plasticidade original; o mundo está pronto e é "duro", resiste à intervenção humana. Isto porque, explicam os Wapishana, a fala perdeu sua força produtiva - propriedade, originalmente, de toda fala. Sua magia hoje só se manifesta no interior do discurso ritual.
O mundo de hoje é, assim, resultado da ruptura de uma ordem primordial, ruptura que diferenciou o tempo e o espaço e provocou a especiação. A especiação, por seu turno, repousou sobre uma distribuição desigual da fala: perderam-na muitas espécies, motivo básico pelo qual se tornaram outras espécies — ou, como gostam de dizer os Wapishana, qualidades —, fazendo com que a fala articulada seja hoje atributo quase exclusivo da humanidade, que a distingue dos outros entes que povoam o mundo. Assim, a fala articulada é, aos olhos dos Wapishana, o que os faz humanos.

Nesta concepção se encapsula a ética que funda o sistema retórico Wapishana: o atributo da fala e seu uso decoroso circunscrevem a condição humana, seu tempo e limites.

G. Calamé-Griaule, em posfácio ao seu Ethnologie et langage (1987), afirma explicitamente que o estudo da noção de pessoa é via privilegiada para uma antropologia da linguagem, em particular, para a estilística, uma vez que a noção de eu subjaz, no mais das vezes, aos modos 
convencionados da expressão. A reflexão sobre a condição humana entre os Wapishana evolve, com efeito, de um vínculo necessário entre a alma e a fala, que o presente artigo busca explorar.

\section{Do silêncio}

A fala articulada, para os Wapishana, é índice de humanidade. Devo notar que não negam, entretanto, um estatuto humano a outros povos: humanos falam, sejam eles brancos, ingleses ou brasileiros, Macuxi ou Wai-Wai. A ininteligibilidade mútua das línguas, ainda que motivo de desentendimento e contenda, não remete, contudo, a uma outra natureza dos falantes. Mas, se a fala é humana por excelência, poder-se-ia deduzir que não humano é o que não fala. Sim e não é a resposta, mas, para obtê-la, há que se buscar os contrapontos possíveis no domínio nãohumano. Detenho-me, para tanto, em uma noção crucial neste domínio, a noção de panaokaru.

Não posso oferecer uma tradução precisa do termo panaokaru (pl.: panaokarunao). Os Wapishana o traduzem genericamente por "bicho", "animal". Em uma primeira acepção, o termo panaokaru aplica-se aos animais selvagens; os animais domésticos, sobre serem panaokaru, são qualificados de wa'uఇ̣ao, nossa criação. Mas o termo panaokaru possui outra acepção, que aqui nos interessa de perto: como explicam os Wapishana, trata-se, em sentido lato, da alma das coisas. Tudo o que existe tem panaokaru, tudo o que a gente lembra, à exceção dos humanos e de uma categoria particular de plantas de que tratarei adiante, caracterizados por outro princípio, udorona.

Vultos, ruídos, imagens cambiantes e apenas entrevistas "nunca ouviu pau rangendo no mato? É isso daí", dizem os Wapishana -, a realidade panaokaruse mede em sintomas, ou efeitos (Viveiros de Castro, 1986, p. 506; veja-se ainda Deleuze, 1974, e Derrida, 1991), que consistem, via de regra, em uma gama variada de doenças, que vão das marcas vermelhas nas pernas das crianças — sinal evidente de que, alta noite, enquanto todos dormiam, foram tocadas por panaokaru —, das feridas que não cicatrizam, até as febres que resultam letais.

Os efeitos panaokarunao guardam como tema comum a predação sobre os humanos, predação cujas modalidades podem variar, seja no vampirismo ou na necrofagia, mas que invariavelmente resulta em doença e morte. Por sua vez, a doença, a morte e os maus odores em geral incluída a menstruação - são estados que atraem a predação panaokaru. Para o panaokaru, dizem os Wapishana, exalamos sempre um odor de caça.

Os panaokarunao flecham os homens - o que é atestado por feridas incomuns, de difícil cicatrização - e cobiçam as mulheres, em particular mulheres menstruadas, que lhes são excepcionalmente atraentes. Até mesmo os meninos são freqüentemente advertidos a não chutar pequenos e indefesos caracóis ou ser cruéis com os lagartinhos pintados, porque kwito tunur, seu pai, irado, pode lhes roubar a alma.

O ardil caracteriza a predação panaokaru, entrelaçando os campos do sexo e da caça: $\underline{2}$ em outras palavras, a sedução erótica é sua armadilha de caça. Inúmeros são os casos de humanos que tiveram sua alma quase ou efetivamente roubada por panaokaru que se lhes apresentou, sob aparência enganosamente sedutora, oferecendo comida e sexo; não raro, assumem a forma de brancos, bonitos, ostentando carros, motocicletas e bolsas repletas de dinheiro.

Indício seguro de que humanos foram atraídos por panaokarunao é a perda de apetite, saciados que ficam pela comida que oferecem. A corte de um panaokaru a uma humana se exerce, com efeito, sobretudo através da oferta de alimento.

Em paralelo ao antialimento que oferta, o sexo com panaokaru, que se realiza, preferencialmente, em período menstrual, é infecundo, traz doença e morte. Se eventualmente resulta em gravidez, esta é igualmente uma antigravidez — cujos sintomas são violento inchaço, dores no ventre e retenção urinária - que não produz crianças, 
apenas água. Noto que, muito embora mais vulneráveis, não apenas as mulheres estão sujeitas à atração pelos panaokarunao; homens igualmente podem ser levados à doença e à morte pela sedução erótica depanaokaru.

Sua realidade é a dos sonhos, dos delírios febris, das viagens xamânicas. Inútil seria sublinhar que não se trata de um grau menor de realidade ante àquela humana, mas propriamente de outra ordem de realidade. Afirmam explicitamente os Wapishana: "sonhando, vemos gente, mas é bicho". E explicam ainda: "panaokaru ninguém vê, só em sonho. É a mesma coisa que você estar em São Paulo e eu sonhar com você, porque acordado não vejo mais." Comer em sonho, fazer sexo em sonho, estabelecer, enfim, o convívio com os panaokarunao em estados oníricos ou febris nos retira da realidade dos vivos: $\underline{\underline{3}}$ "tudo eles têm, por isso pegam a gente e dão comida, mingau, a gente não quer comer mais. Comemos em sonho." Atração fatal, sem dúvida, que nos faz desistir da existência humana para adentrar o campo do outro, percurso que poucas vezes tem volta.

Em contrapartida, pode-se sugerir que estados que constituem descentramentos em relação à medida humana atraem, metonimicamente, à esfera panaokaru: o jejum, transgressão da boa dieta alimentar, bem como o desejo frustrado e a paixão obsedante - carência e excesso, respectivamente, diante do pacto amoroso — predispõem o sujeito à sedução predatória do panaokaru. Nesta linha, o luto, a doença e a menstruação - situações consideradas dipshan, podres - constituem limites extremos de descentramento, que oferecem maior perigo de predação.

Importa-nos reter que o caráter enganoso da imagem panaokaru igualmente se aplica à sua voz. É opinião geral que panaokaru não fala, possuindo apenas um grunhido ininteligível que em nada se assemelha à fala humana. O xamã, marinao, pode, no entanto, entender seu grunhido: quando presente em uma sessão xamanística, nenhum dos assistentes pode compreender sua cantiga, apenas o marinao pode explicá-la.
Isto poderia nos levar a entender que, embora ininteligível ao comum da gente, panaokaru possuísse língua própria. Tal não se dá, porém: à falta de língua própria, panaokaru é imitação da voz humana, apenas imita a fala articulada.

Para além da ininteligibilidade, maior vácuo comunicativo se impõe, pois panaokaru é voz que não se escuta do interior da sociabilidade humana: "a gente não entende nem escuta fala de panaokaru". De modo análogo ao que vimos ocorrer com a imagem, dar ouvidos a esta fala leva necessariamente à doença e, em um limite, à morte:

Kwap'taka é gente mesmo, quando fala com a gente, ficamos doentes.Kamara[o eco] também. Yatchim [a gripe e a malária] gosta de andar no sol quente, por isso não se pode levar criança no sol quente, porque bicho fala para ela — não precisa encostar, só fala de longe —-, criança fica doente, fica doida, chora. Faz mal conversar com bichos, a gente fica doente. A fala deles é diferente. Não presta conversa de bicho.

Comunicação de tal sorte deve ser evitada, portanto, sob pena de inviabilizar a comunicação com os vivos, inviabilidade que a morte física expressa. E, como já se percebe, a comunicação com a esfera panaokaru vai se tornando possível à medida que enfraquecem os laços comunicativos com os vivos, até que cesse de vez toda a possibilidade de diálogo humano. Isto afirmam os Wapishana de forma definitiva: "Quanto mais doente, mais perto o panaokaru; de longe, é quando a doença começa".

Mas, para bem apreender a antifala panaokaru, devemos retornar aos fragmentos da cosmogonia dos quais partimos para esta discussão. Como disse anteriormente, o advento do mundo atual operou-se sobre uma distribuição desigual da fala; na especiação que então teve lugar, todos os entes se transformaram em puri, magia. A força criativa de sua palavra ficou, assim, nas encantações que hoje só podem ser atualizadas pela fala humana. Para os Wapishana, tal ânimo é impessoal; estritamente pessoal é a alma humana, expressa na fala que os animais há muito perderam. Tomando em consideração a glosa Wapishana para o termo panaokaru como "bicho" ou "animal", poder-se-ia 
sugerir que panaokaru constitui um princípio genérico de animalidade que, note-se, virtualidade de todos os existentes, não se esgota na esfera da natureza. É virtualidade do homem, inclusive.

Tratando de um princípio essencial das espécies naturais para os Amuesha na Amazônia peruana, Santos-Granero (1991, pp. 79-80) observou que o fato de as espécies naturais serem manifestações de uma essência fala da imortalidade atribuída à natureza, sua cíclica recorrência em contraponto à humanidade que, mortal, impõe-se a tarefa de buscar a imortalidade. Os Wapishana parecem montar diferentemente sua equação: a alma das coisas possui recorrência, afeta as coisas que crescem e morrem, mas carece de transcendência, a que só a alma humana pode aceder. 4 Não por acaso os maus odores atraem a predação panaokaru; atraem-na as coisas fadadas à vida e à morte, à deterioração.

Mas, para demonstrá-lo, há que se buscar o sentido da transcendência para os Wapishana, segredo que apenas uma categoria vegetal específica detém plenamente.

\section{Do canto}

A classificação botânica dos Wapishana compreende três grandes categorias: karam'makao, as plantas da mata, selvagens; wapao'ribao, as plantas domesticadas, cultivadas na roça; e, por fim, categoria singular, oswapananinao, cuja tradução, de simplicidade apenas aparente, seria "as nossas plantas" (wa, pronome possessivo, primeira pessoa do plural; pananu, panakaru, planta; nao, pl.).

Distinguem-se os wapananinao das demais categorias, inicialmente, pelo fato de se encontrarem associados à magia; não apenas porque acompanham fórmulas mágicas — e, nesse caso, são seu veículo —, mas porque são geradores de magia.

Os wapananinao, pelo levantamento a que pude proceder, são, em sua maioria, ciperáceas e cactáceas. Cactos e tubérculos, em particular estes últimos, caracterizam-se pelo seu excelente perfume, propriedade que os Wapishana enfatizam. Outra propriedade fundamental é a secura: os wapananinao, dizem os Wapishana, brotam no inverno e atingem seu auge na aridez do verão. Fora da terra, são mantidos secos; secos, os tubérculos entram na confecção do pequeno maracá do kamapazo, uma das modalidades do xamanismo. Secos, ainda, oswapananinao são ingeridos, em infusão de água fria, pelo iniciando no xamanismo, ingestão que assegura que passarão a fazer parte da pessoa do xamã. Assim, para os Wapishana, sequidão e perfume fazem doswapananinao uma forma de vida singular, única, radicalmente diferente de humanos ou animais, que não podem prescindir da umidade para a vida.

A posse e uso de plantas mágicas não devem ser do conhecimento público. Além disso, sua posse e uso variam conforme o sexo: há usos específicos para homens e mulheres, e seu conhecimento é vedado de um sexo a outro, sob pena de perderem a eficácia. Há ainda uma divisão entre o uso por indivíduos comuns - que os utilizam de forma laica, para garantir seu próprio sucesso, e o de seus cães, na caça, na pesca, na agricultura, no amor e tantos mais projetos e interesses humanos - e por xamãs. Estes últimos possuem não só um conhecimento de um espectro mais amplo de plantas, como fazem delas, como mencionei anteriormente, um uso potenciado.

Os wapananinao são obtidos freqüentemente através de troca, figurando como item de extremo valor. Só a troca é o meio possível de sua circulação; a venda, aliás, é considerada reprovável, além de ineficaz, porque, aborrecidos, os wapananinao recusar-se-iam a seguir seus novos possuidores, bem como vingar-se-iam daqueles que ousaram lhes ceder a terceiros.

Aqui se desvela a propriedade fundamental dos wapananinao, a de, tal como os humanos, possuirem uma alma,udorona, princípio que lhes confere intenção e vontade. Donos de vida própria: tal é sua diferença radical com relação às outras categorias botânicas, pois ninguém os cultiva ou cria, mas eles apenas permanecem com quem deles melhor cuida. Se se desagradam dos cuidados que lhes 
são dispensados, os wapananinao mudam-se, o que é atestado pela morte - aparente — da planta. Digo aparente porque, à diferença dos humanos que com eles compartilham uma alma, os wapananinao nunca morrem.

Por possuirem em comum com os humanos uma alma - udorona -, os wapananinao possuem ainda o atributo da fala que dela decorre: "os tajás são gente, pode-se conversar com eles". Porém, o verbo possuir não é o que melhor descreve esta relação: para os Wapishana, os wapananinao são alma, que por sua vez é a potência da fala em grau eminente, o canto. Em canto os wapananinao se manifestam, e mesmo no interior de um maracá vivem, falam e, sobretudo, cantam.

Alma/palavra, enfim, despida da matéria que se corrompe e perece. A secura parece, assim, conotar a imortalidade que lhes é própria. Infensos à deterioração e ao apodrecimento, os wapananinao se recusam a agir sob a invocação de enlutados ou para estes, porque lhes aborrece o odor putrefato da vizinhança da morte. Mulheres menstruadas igualmente não podem utilizar os wapananinao, nem o marinao pode fazê-lo por elas, porque os wapananinao não gostam do cheiro do sangue. Tampouco as grávidas podem utilizá-los, por seu peso excessivo. Tal aversão, a meu ver, não deriva de serem eles suscetíveis a seu contágio, mas antes porque representam o oposto lógico da podridão: imortais, imputrescíveis, aromáticos, os wapananinao configuram o inverso das coisas deterioráveis e malcheirosas.

Por contraste, esboçam-se na imagem dos wapananinao os fundamentos de uma fisiologia: a matéria viva, para os Wapishana, pressupõe a dosagem de umidade, calor e, pode-se acrescentar, peso. Possuem-na os humanos, animais e vegetais, mas esta mistura é também a que leva os corpos à corruptibilidade.

Com os wapananinao dá-se o contrário: nascidos da umidade da terra, durante a estação das águas, tubérculos ou cactos túrgidos alcançam sua plenitude na estação seca, perdendo mais e mais a seiva e atingindo a leveza aérea do canto. Leveza de uma alma sem corpo que só eles, dentre todas as coisas, podem atingir, com exceção dos xamãs que, ingerindo-os, também tornam-se, eles mesmos, leves e incorpóreos.

Dotados de alma, o que vale dizer autonomia, ânimo e vontade próprios, os wapananinao, por serem diferenciados das outras espécies vegetais, propõem ainda uma relação com os homens que não pode ser lida sob a ótica da produção, pois, lembremos, à diferença de todos os outros cultivos que são reconhecidos como produtos do trabalho humano, dos wapananinao se diz que ninguém cultiva, apenas cuida. Os sentidos deste cuidar merecem exame.

Dois epítetos aparentemente contraditórios qualificam a relação entre humanos e wapananinao: de um lado, referidos em português, os wapananinao são ditos xerimbabos do marinao; de outro, são ditos marinaodani, filhos do xamã. $\mathrm{O}$ aspecto animal de estimação esclarecer-se-á adiante; detenho-me, por ora, na filiação.

Tratando da relação dos Achuar com suas plantas cultivadas, Descola (1986) afirma que a filiação postulada entre mulheres e as plantas de sua roça, que sugam seu sangue, consiste em metáfora para expressar o desgaste provocado por uma relação que consome o esforço feminino em prol da reprodução, desgaste que seria o atributo compartilhado entre os filhos e o cultivo: ambos extraem as forças de mulheres.

Antes que metáfora, os Wapishana utilizam a comparação para referir à relação que mantêm com as plantas mágicas, enfatizando como termos para tal comparação o zelo, o cuidado e o respeito mútuo que devem pautar a relação entre pais e filhos: "Planta de marinao é filho dele, porque ele planta, cuida, defuma com tabaco todo dia. Cuida como a gente cuida filho. Todos que têm panakaru podem cuidar como filhos, dando tabaco."

Assim, a leitura de uma tal relação sob a perspectiva da linguagem figurada, embora plausível, não me parece suficiente. Se não, vejamos. 
"A mandioca é nossa mãe", dizem com freqüência os Wapishana, para em seguida explicitar sua intenção de metáfora: "porque nos alimenta". Outro, no entanto, é o estatuto concedido aos wapananinao: aqueles que cuidam de wapananinao e as plantas sob sua proteção tratam-se, friso, reciprocamente, por termos que indicam filiação. Assim, em uma sessão xamanística, oswapananinaoassociados ao xamã o tratam pelo termoõdaru — meu pai — ou õdaro — minha mãe, no caso excepcional de uma xamã mulher —, bem como são tratados por õdani - meu filho. A relação de filiação não é exclusiva do xamã: todos aqueles que cuidam de panakaru devem cuidar como fazem com seus próprios filhos, zelando pelo seu bem-estar. Além disso, quando aparecem aos humanos, em sonhos, vêm sob a forma dos filhos que já temos, falam conosco e fazem suas demandas, em geral água e tabaco.

Assim sendo, não creio que se possa falar, como o faz Descola, em uma filiação em sentido próprio, da qual a relação com as plantas cultivadas seria uma extensão metafórica. Trata-se, a meu ver, de uma afirmação literal de filiação, mas, à diferença dos filhos que geramos da carne, estes são filhos incorpóreos, feitos só de alma/palavra, e concernem diretamente à reprodução do conhecimento esotérico, da magia.

Para os Wapishana, portanto, a relação com crianças e plantas mágicas, ambas portadoras de alma, pressupõe a construção de uma relação ativa e recíproca, que envolve o ensinamento como forma privilegiada do zelo. Assim, a meu ver, se explica ainda o fato de que é preciso ensinar os wapananinao a cantar.

Sim, porque é preciso ensiná-los a cantar. Como as crianças, os wapananinao têm o potencial de fala, que deve ser desenvolvido: aquele que passa a cuidar de um panakaru o ensina a cantar. Em contrapartida, após seu aprendizado, o panakaru passa a ter, por assim dizer, autonomia de canto: cantará e mesmo poderá ensinar, em sonhos, novos cantos ao humano que dele cuida.
Passemos ao segundo aspecto, o de animal de estimação. Tudo o que até aqui alinhamos converge para colocar os wapananinao, alma/canto, sob a égide da incorruptibilidade e, assim, da imortalidade. Estas propriedades os colocariam em oposição simétrica aos panaokarunao, marcados, como vimos, pela atração do putrescível e mau cheiroso.

Se assim fosse, tudo não passaria de um fácil e, até certo ponto, desinteressante dualismo. Porém, não creio que se possa capturar um ser ou natureza wapananinao: define-os, antes, uma conduta e o fim a que se destinam.

Indiquei anteriormente que há, para os wapananinao, uma utilização laica e uma especializada. Certo é que a fronteira entre ambas é tênue, mas basicamente traçada pelo canto. Este, por sua vez, é, como vimos, potencialidade da alma, mas, acrescentam os Wapishana, potencialidade ativada pelo alimento em tabaco. Assim, a utilização laica pode, em princípio, dispensar o canto, mas de modo algum o uso especializado, pois a magia pende do canto.

Mas nem só de tabaco se alimentam os wapananinao: o sangue é considerado um ativador, tão ou mais potente do que o tabaco, de sua magia. Dizem os Wapishana que o sangue lhes refina a arte, seja de cura, de caça ou de vingança.

Eis seu paradoxo: sangue e tabaco concedem o canto em mais alto grau, mas ao mesmo tempo desatam a virtualidade animal dos wapananinao. Alimentados com sangue e tabaco, os wapananinao podem se manifestar sob forma animal. Assim, saro, a lontra, se manifesta na forma deste animal, bem como baudokoru, a onça, se apresenta como tal. "Pananu vira bicho conforme sua qualidade", dizem os Wapishana, ou seja: em princípio, a forma manifesta é particular a cada espécie de planta. No entanto, formas das mais variadas já foram reportadas sem que houvesse um vínculo básico à espécie de planta, como jacamins, tamanduás, ou mesmo gatos. Em um limite, todos os wapananinao podem tomar qualquer forma animal e humana; mas, ainda que sob forma animal, para os 
Wapishana, não deixam de ser gente, posto que não se apaga o fato de que possuem uma alma.

Este estatuto ambíguo parece-me conjugar os dois qualificativos contraditórios dos wapananinao, que mencionamos acima: de "filhos" e "xerimbabos". Enquanto animais de estimação, há que buscar domesticálos, direcionando-os a proteger os que deles cuidam: onças tomam conta de casas na ausência de seus donos, guiamnos na mata e mesmo os levam para casa quando estão bêbados. No entanto, sua ferocidade é algo que pode escapar ao controle: tomando o que os Wapishana chamam agudamente de "um gosto por sangue", oswapananinao podem passar a caçar indiscriminadamente animais e humanos. Dizem os Wapishana que há aqueles que "estragam" seus xerimbabos, isto é, lhes dão sangue para lançá-los à vingança, buscando precisamente a devoração de humanos: do canto passam, assim, à devoração.

Para domesticar os wapananinao, há que não deixar emergir sua virtualidade animal, o que significa não lhes permitir o sangue, ainda que isto implique perda de magia. É, pois, a alta magia figura de excesso que, enquanto tal, escapa aos desígnios humanos e cobra um alto preço em desastre e morte.

Nesse sentido, os wapananinao são aquilo que sua conduta faz deles. O mesmo se dá com os homens.

\section{A medida humana}

Pensadores refinados, os Wapishana não postulam que a alma habite suporte ou recipiente corporal, nem que se localize — imagem a que estamos habituados — em uma parte específica do corpo, seja coração ou cabeça. O princípio que venho designando como alma, udorona, é o princípio vital propriamente dito, força que, por si, nos movimenta e anima; expressa-se no batimento cardíaco, na respiração e, exponencialmente, na fala articulada.Udorona existe na pulsação, na respiração e na fala; sabe-se que há, quando há sangue e voz. Indissociável do corpo, udorona é o princípio dinâmico que lhe confere movimento, autonomia e vontade. Sua realidade é ainda apreendida na sombra forte que projetamos ao sol.

A morte se atesta pela total cessação da respiração, da pulsação e da fala, o que pode ocorrer sem ser em definitivo, nos desmaios, no coma alcoólico e demais lapsos da consciência, eventos todos designados pelo mesmo verbo, (x) maokan, morrer. $\mathrm{Na}$ morte, diz-se "udorona umakon naa", a alma se vai, ou, de forma mais eloqüente, diz-se que alguém se calou, umashadan. O destino após a morte não é objeto de alta elaboração; ao contrário, diante da questão, os Wapishana apenas reiteram que "ninguém sabe para onde vai udorona". Ir-se parece mais um circunlóquio para tratar de uma questão mais complexa: a morte não representa o fim daudorona, mas o fim de sua existência individuada; na morte, o que não perdura é a pessoalidade. Ainda que alguns creiam que udorona possua uma existência após a vida terrena, esta é uma existência sem identidade, para a qual opera o paulatino estranhamento dos mortos.

Destino diverso, note-se, seguem apenas os xamãs após a morte: permanecem em uma árvore chamada Toronai, que existe no alto, no céu ou no topo das serras mais altas e inacessíveis, onde se casam novamente e podem ter filhos.

Esvaindo-se a udorona, a morte produz dois outros aspectos que, embora distintos entre si, são ambos designados, eufemisticamente, porawaru, o vento. Udikini, ao contrário da força vital constituída na udorona, é a sombra mais fraca que projetamos ao sol. São ditos udikini os retratos e as imagens da televisão; tal como estes, udikini não passa de uma sombra pálida que, ocasionalmente, aparece aos vivos: "você reconhece, mas ela não está mais, ela já morreu". Inócua aos vivos, udikini pode apenas produzir barulhos nos locais que um dia freqüentou. Às vezes, esconde-se nos redemoinhos, mas, via de regra, pode ser percebida na casa em que habitava, pois procura estar junto a seus antigos pertences terrenos. 
Poder-se-ia sugerir que udikini, definida pelos Wapishana como sombra, é a lembrança que o morto carrega de seus pertences em vida, mas, reversamente, lembrança do morto evocada pelos objetos que um dia foram seus. Lembrança que vai pouco a pouco cedendo, ao entrarem os objetos em novo uso e nova posse: em seis meses, mais ou menos, dizem os Wapishana, udikini desaparece.

Outra coisa é desfazer-se a lembrança de alguém, um rosto e uma história: isto constitui o $m a^{\prime} c h a i$, termo que se refere tanto ao cadáver quanto ao seu espectro. "Udorona — dizem os Wapishana - ninguém sabe para onde vai; quem volta éma'chai."

À diferença de udikini, apego do morto aos seus pertences, $m a^{\prime} c h a i$, a sombra do morto, é seu apego aos entes queridos, às relações sociais que em vida entreteve. Mas este apego, se instituinte de uma sociabilidade na vida, na morte ganha sentido oposto: pode-se subscrever para os Wapishana o que demonstrou Carneiro da Cunha (1978) para os Krahó, ou seja, mortos são aqueles que se passaram para o outro lado, abandonaram os vivos, e, assim sendo, aceitar seu convívio seria abrir mão da vida em sociedade. A saudade do morto - em duplo sentido, a saudade que ele sente e sua contrapartida, aquela que dele se sente provoca nos vivos uma nostalgia letal (Carneiro da Cunha, 1978; Viveiros de Castro, 1986).

Ma'chai, certeza de um corpo que se desfaz, exala um odor pútrido que tudo contamina - coisas, animais e homens. As opiniões divergem: para uns, a ameaça representada peloma'chai cessa com a total decomposição do cadáver; para outros, o espectro permanece, independente da decomposição de seu corpo, e vai morar na mata e, sobretudo, nas serras, de onde ocasionalmente vem rondar os viventes, para levá-los consigo. A divergência é significativa, pois refere-se precisamente à medida da lembrança do morto entre os vivos.

Pois que de outra coisa trata oma'chai, senão da lembrança do morto entre os vivos? Presença de uma ausência, na análise inspirada de Viveiros de Castro (1986, p. 505), memória insistente de um corpo, de uma individualidade.
Talvez, por isso, hesitem os Wapishana em determinar um período para a ameaça posta pelo ma'chai: lembra-se de nós enquanto do morto nos lembramos.

$M a^{\prime} c h a i$, o cadáver e seu espectro, é, para os Wapishana, a porção panaokaru do ser humano. Nesta linha, a atração quema'chaiexerce sobre os vivos é vista como predação, atingindo os doentes e os tristes: "muitas vezes a pessoa anda triste, pensando em quem morreu, é mais fácil ma'chaiaparecer. Verma'chaié adoecer". Claro está que maior vulnerabilidade se encontra no espaço da consangüinidade, onde é mais intensa a presença doma'chai.

Novamente, os convites insistentes do ma'chai se fazem, sobretudo, mediante a oferta de alimento que, inverso simétrico da partilha que institui sociabilidade, só resulta em doença e morte: "Ma'chai provoca dor de barriga e dor de coração, porque em sonho omáchainos dá comida e bebida". Para seduzir os vivos para que o sigam, em particular quando vê um deles doente, oma'chai passa a alimentar o doente, que então piora, porque não quer mais se alimentar: "é a mesma comida dos vivos; se comemos no sonho não queremos mais a nossa comida".

Tal negação de humanidade se expressa, de modo equivalente, no código comunicativo. A sombra do morto propõe um antidiálogo, expressando-se em um murmúrio ininteligível. Pelos motivos que já examinamos, a comunicação com ma'chai só se estabelece em situações de descentramento da alma, nos estados oníricos ou febris.

De um lado, a neutralização doma'chai requer seu esquecimento. Por tempo variável, indeterminado mesmo, a ausência do morto se fará sentir, provocando a nostalgia, a tristeza. O paulatino estranhamento dos mortos é o antídoto para a ameaça que representa ao bem-estar dos vivos.

Ninguém o vê, ninguém o escuta, ninguém, em suma, o reconhece. $\mathrm{O}$ apagamento de sua memória é o requisito para a continuidade da vida. O esquecimento é, assim, imperativo, como explicam os Wapishana, recorrendo 
sempre à comparação com o mundo vegetal: "veja o algodão, nunca lembra o pé de onde foi arrancado".

Em resumo, ma'chai, lembrança cifrada no odor pútrido exalado pelo cadáver, memória da carne que se desfaz, é virtualidade panaokaru do homem que tende ao podre. Sua contrapartida é a fala, princípio ativo, ânimo, alma.

Udorona, como anunciei anteriormente, é princípio vital que se encontra na fala, no sangue, na respiração; prova disso, dizem os Wapishana, é que quando morremos ficamos brancos e frios.

À diferença da respiração e da fala, o sangue é componente da pessoa transmitido e partilhado. Para os Wapishana, o sangue, com efeito, é obtido por transmissão: recebemo-lo de pai e mãe, em partes igualmente distribuídas. É, além disso, partilhado: irmãos, pais e filhos de Ego possuem o mesmo sangue, constituindo, assim, propriamente o grupo que Ego reconhecerá como seus consangüíneos. Tal noção se expressa no termo óribienao, que, traduzindo literalmente, significa "meus muitos", ou melhor dizendo, "os muitos de mim". Não se incluem neste grupo os parentes colaterais, nem os afins que não são consangüinizados — divergindo, assim, os Wapishana do cenário guianense —, em que pesem o nascimento dos filhos ou a longa co-residência.

Os limites da consangüinidade estão dados neste grupo, limites estes que são ditosõtokon, "minhas pontas": "ponta é como planta, o que nasce do mesmo pé". Em tese, encontram-se excluídas do grupo de consangüíneos a segunda geração ascendente e a segunda geração descendente em relação a Ego: "Avós não são pontas, porque já morreram, já acabou. Chama avô mas não é ponta". Explicam os Wapishana que, se vivos, os avós podem ser considerado sõtokon, mas não mais o serão após sua morte. Essa condição transitória dos avós tem implicações sobre a relação que mantêm com os netos, em particular no resguardo pela doença e outras situações que envolvem o cálculo do sangue. Tal concepção tem ainda implicações sobremodo importantes na transmissão narrativa, pois é precisamente a ausência possível de um vínculo de sangue entre Ego e a segunda geração ascendente que permite um vínculo de linguagem (veja-se Gow,1991, e Farage, 1997).

A respiração é componente pessoal da alma: no ventre materno não a possuímos; apenas a obtemos quando, pela primeira vez, inspiramos. A respiração, em certa medida, acompanha o valor da fala, questão que se apreende com maior nitidez no contexto da magia: soprar e falar são atos homólogos, que surtem o mesmo efeito encantatório, por serem ambos alma.

Sopro, fala, o atributo fundamental da alma é a leveza. A alma - sopro e fala conjugados na magia - é o que, no homem, pode ainda restaurar a criatividade da fala original, seu poder de transformar o mundo.

Por sua vez, a fala, do ponto de vista Wapishana, é índice exponencial da alma. Sua existência no homem é o que o singulariza, o que não o deixa diluir-se entre as coisas do mundo. Índice também da vida humana, comprova-o, como disse acima, o murmúrio rouco e inaudível dos mortos, cuja inteligibilidade é sinônimo de morte.

A fala é, ainda, um princípio eminente da razão. Crianças pequenas são ditasmadoronan, termo cuja tradução literal é "sem alma", porque ainda não falam. De modo correlato, querem com isso dizer os Wapishana que crianças não têm discernimento — "criança não tem juízo" —, motivo pelo qual se lhes deve perdoar as tolices que cometem. Ambos, fala e discernimento, desenvolver-se-ão concomitantemente no processo de socialização do indivíduo, culminando em plena sociabilidade. Assim, em seu auge, a faculdade de falar perfaz o homem, aquele que é capaz de dialogar com seus semelhantes. Nesta linha, dizse ainda madoronan com referência àqueles que estão fora de si, por estarem seja bêbados, seja tomados por sentimentos violentos, como a raiva, o ressentimento, a paixão: estes agem erraticamente e não falam, recusam o diálogo.

A fala é princípio estritamente pessoal: "Para formar uma criança, os pais ajudam com o sangue; o sopro e a fala são dela mesmo. A gente ensina a falar, mas a udorona da gente não pode fazer o outro falar". Em analogia ao que vimos 
ocorrer com as plantas wapananinao, o potencial de fala precisa ser desenvolvido socialmente: às crianças, evidentemente, se ensinam a falar. Este fato, que poderia passar por corriqueiro aos nossos olhos, para os Wapishana se reveste de alto valor simbólico, dada a equivalência entre a fala e a alma: ensinar a falar é processo de humanização, que só ocorre no interior de plena sociabilidade.

Além de pessoal, a fala é princípio cumulativo, que só encontra sua plenitude na velhice, quando, para os Wapishana, somos mais alma do que corpo. Nesta concepção imbrica-se o conhecimento, necessariamente envolto na competência oratória; falar bem é o corolário da sabedoria, que só existe na proporção da alma.

Em suma, correlato da alma, a fala é, da perspectiva dos Wapishana, valor central na definição do humano. Mas, vale insistir, é entre os extremos do silêncio e do canto que a medida humana se instaura. Silêncio e canto são, como vimos, virtualidades do homem; de sua dosagem exata que não é nem o peso da animalidade, nem a existência imponderável das plantas wapananinao - resulta a comunicação entre semelhantes. Diálogo é, enfim, o quinhão dos homens.

\section{NOTAS}

1 Os Wapishana, povo de filiação lingüística Maipure/Arawak, atualmente em número estimado de 10 mil a 11 mil indivíduos, habitam o interflúvio Branco/Rupununi, região de fronteira entre Brasil e República da Guiana.

2 Veja-se Descola (1986) quanto à mútua sedução entre caçador e caça para os Achuar.

$\underline{3}$ Tema que, aliás, evoca vivamente a relação dos Krahó com seus mortos. Veja-se Carneiro da Cunha (1978).

4 Veja-se a discussão magistral de J.C.Crocker (1985) acerca do princípiobopepara os Bororo.

\section{BIBLIOGRAFIA}

CALAMÉ-GRIAULE, G. (1987), Ethnologie et language: la parole chez les Dogon. Paris, Institut d'Ethnologie, Musée de l'Homme.

CARNEIRO DA CUNHA, M. (1978), Os mortos e os outros: uma análise do sistema funerário e da noção de pessoa entre os indios Krahó. São Paulo, Hucitec.

CROCKER, J.C. (1985), Vital souls: Bororo cosmology, natural symbolism and shamanism. Tucson, University of Arizona Press.

DELEUZE, G. (1974), "Platão e o simulacro",inG. Deleuze,Lógica do sentido, São Paulo, Perspectiva.

DERRIDA, J. (1991), A farmácia de Platão. São Paulo, Iluminuras.

DESCOLA, Ph. (1986), La nature domestique. Symbolisme et praxis dans l'ecologie des Achuar. Paris, Editions de la Maison des Sciences de l'Homme.

FARAGE, N. (1997), As flores da fala: práticas retóricas entre os Wapishana. Tese de doutorado, São Paulo, Programa de Pós-Graduação em Letras, USP.

GOW, P. (1991), The event of myth. LSE seminar paper, manusc.

SANTOS-GRANERO, F. (1991), The power of love: the moral use of knowledge amongst the Amuesha of Central Peru. Londres, The Athlone Press.

VIVEIROS DE CASTRO, E. (1986),Araweté: os deuses canibais. Rio de Janeiro, Jorge Zahar Editor.

* Trabalho apresentado ao GT História Indígena e do Indigenismo, no XX Encontro Anual da Associação Nacional de Pós-Graduação e Pesquisa em Ciências Sociais (Anpocs), 22-26 de outubro de 1996. 